\title{
Management of asymptomatic silicone-injected breast with reduction mammoplasty
}

\author{
Theddeus Octavianus Hari Prasetyono, Patricia Marcellina Sadikin \\ Department of Surgery, Division of Plastic Surgery, Faculty of Medicine, Cipto Mangunkusumo Hospital, University \\ of Indonesia, Jakarta, Indonesia
}

Address for correspondence: Dr. Theddeus Octavianus Hari Prasetyono, Department of Surgery, Division of Plastic Surgery, Faculty of Medicine, Cipto Mangunkusumo Hospital, University of Indonesia, Medical Staff Building, $4^{\text {th }}$ floor, Jl. Diponegoro 71 Jakarta 13410 Indonesia. E-mail: teddyohprasetyono@yahoo.com

\section{ABSTRACT}

Even though Silicone injection for breast augmentation has been related to disastrous long-term effects and complications, some patients do not develop significant symptoms at all (asymptomatic). Unfortunately, the management of asymptomatic Silicone-injected breast is still unclear and has never been reported exclusively. We present two cases of asymptomatic patients with a history of liquid Silicone injections who refused to have a mastectomy. They were concerned with the breast ptosis and chose to undergo reduction mammoplasty to improve the appearance of the breasts. Magnetic resonance imaging may be useful as an additional screening tool to confirm the diagnosis and exclude the presence of malignancy in breasts with injected Silicone. We believe that breast reduction may be the alternative option for women with a history of liquid Silicone injection who have no symptoms but desire to preserve their breasts and improve their aesthetics.

\section{KEY WORDS}

Breast; magnetic resonance imaging; mammaplasty; mastectomy; Silicone

\section{INTRODUCTION}

oft tissue augmentation by means of illicit injections of unknown substances has led to disastrous long-term effects and complications. Regrettably, this practice is still carried on by non-medical practitioners using adulterated injection materials for treating uninformed patients who choose cheaper and easier options. In fact, the patients who came to plastic surgeons with complications are just a small number of

\begin{tabular}{|l|l|}
\hline \multicolumn{2}{|c|}{ Access this article online } \\
\hline Quick Response Code: & Website: \\
\hline & www.ijps.org \\
\cline { 2 - 2 } & Dol: \\
\hline
\end{tabular}

patients among the multitude of victims who actually had the injections.

Until now, there is no guideline regarding the diagnosis and management of breasts injected with Silicone, although several studies have proposed algorithms for the management of "symptomatic" injected breasts..$^{[1-3]}$

\footnotetext{
This is an open access article distributed under the terms of the Creative Commons Attribution-NonCommercial-ShareAlike 3.0 License, which allows others to remix, tweak, and build upon the work non-commercially, as long as the author is credited and the new creations are licensed under the identical terms.
}

For reprints contact: reprints@medknow.com

How to cite this article: Prasetyono TO, Sadikin PM. Management of asymptomatic silicone-injected breast with reduction mammoplasty. Indian J Plast Surg 2015;48:317-20. 
For asymptomatic injected breasts, the management is still unclear and has never been reported exclusively. Herein, we present two cases of asymptomatic patients with a history of liquid Silicone injections who refused to have a mastectomy and chose instead to undergo reduction mammoplasty to enhance the appearance of their breasts. The controversy regarding the assessment and management of asymptomatic Silicone-injected breasts is our main debate.

\section{CASE REPORT}

\section{Patient no. 1}

A 45-year-old woman with a history of bilateral breast augmentation with liquid Silicone injections 10 years earlier visited our clinic. The patient wished to have a better breast shape. She denied any redness, pain, skin changes or nipple discharge in either breast. Her medical status was unremarkable. Family history of breast cancer was absent.

On physical examination, there was breast ptosis grade two and multiple hard, solid masses could be palpated throughout both breasts [Figure 1]. There was no pain, skin alterations, nipple areola complex (NAC) or axillary

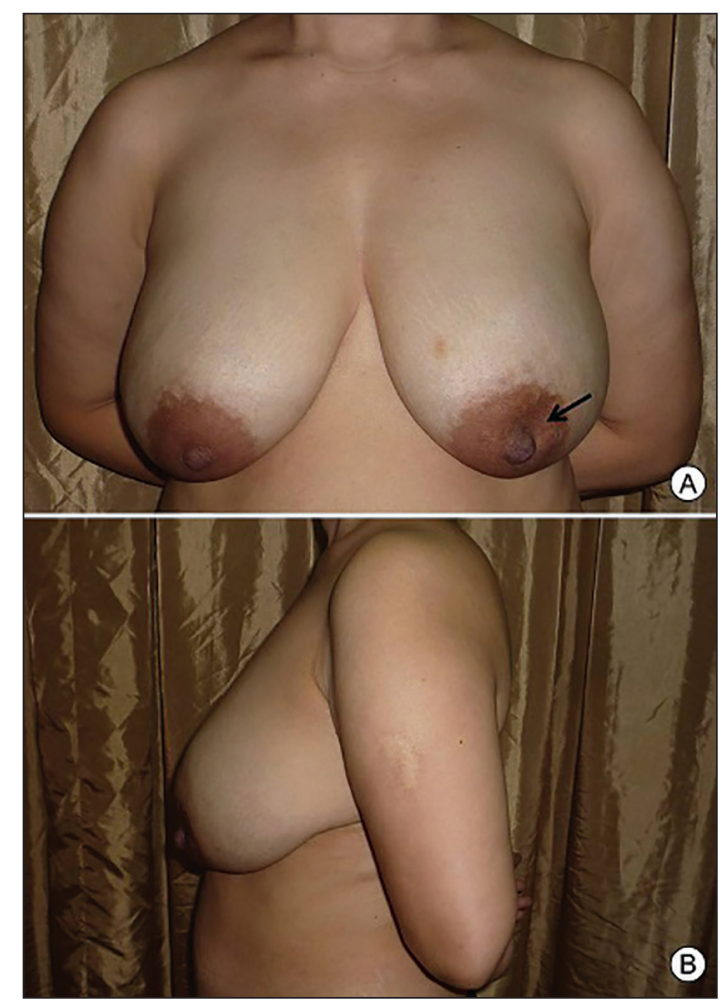

Figure 1: Preoperative view. It shows ptotic large breasts without any visible deformity apart from a notch in the left areola (black arrow) due to uneven distribution of the Silicone masses. (a) Anterior view (b) lateral view lymph node involvement. Mammogram and magnetic resonance imaging (MRI) results were consistent with bilateral breast Silicone granuloma [Figures 2 and 3].

The patient was given two options:

1. Bilateral subcutaneous mastectomy and immediate reconstruction with autologous tissue, or

2. Breast reduction.

She decided to undergo breast reduction surgery. The technique of reduction mammoplasty used was supero-medial pedicle with a vertical scar. The volume of breast tissue removed from the right and left breasts was $250 \mathrm{~g}$ and $216 \mathrm{~g}$, respectively. The histopathology examination showed breast tissue infiltrated with small and large vacuoles and chronic inflammatory cells. It was consistent with breast siliconoma. Signs of malignancy were not found in the specimen.

At 22-months follow-up, the patient had no complaint with her current breast shape and her nipple sensation was intact [Figure 4].

\section{Patient no. 2}

The second patient was a 36-year-old woman, $\mathrm{G}_{3} \mathrm{P}_{3} \mathrm{~A}_{0}$, who came with similar complaints, medical history, physical examination and mammography results. The sonographic image showed diffuse multiple cystic lesions covering the fibroglandular breast tissue and infiltrating the subcutaneous layer. This patient also underwent breast reduction procedure like the first patient. She experienced uneventful healing and was satisfied with the result up to 6-months follow-up. Similar to patient no. 1, follow-up mammogram and MRI could not be taken because she refused to have them.

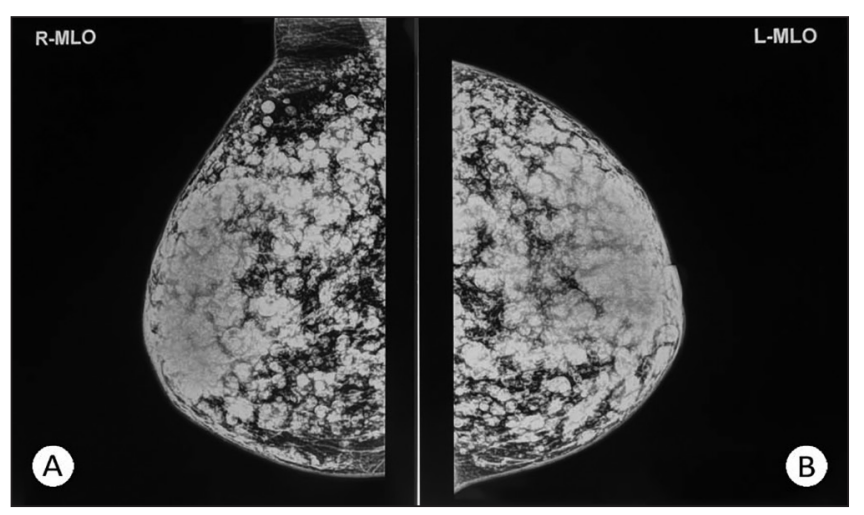

Figure 2: Mammography image. It revealed the presence of diffuse multiple nodules in both breast parenchymas, in various sizes; however, the presence of stellate lesion and micro-calcification was unclear. Mediolateral oblique view of the right breast (a) and the left breast (b) 


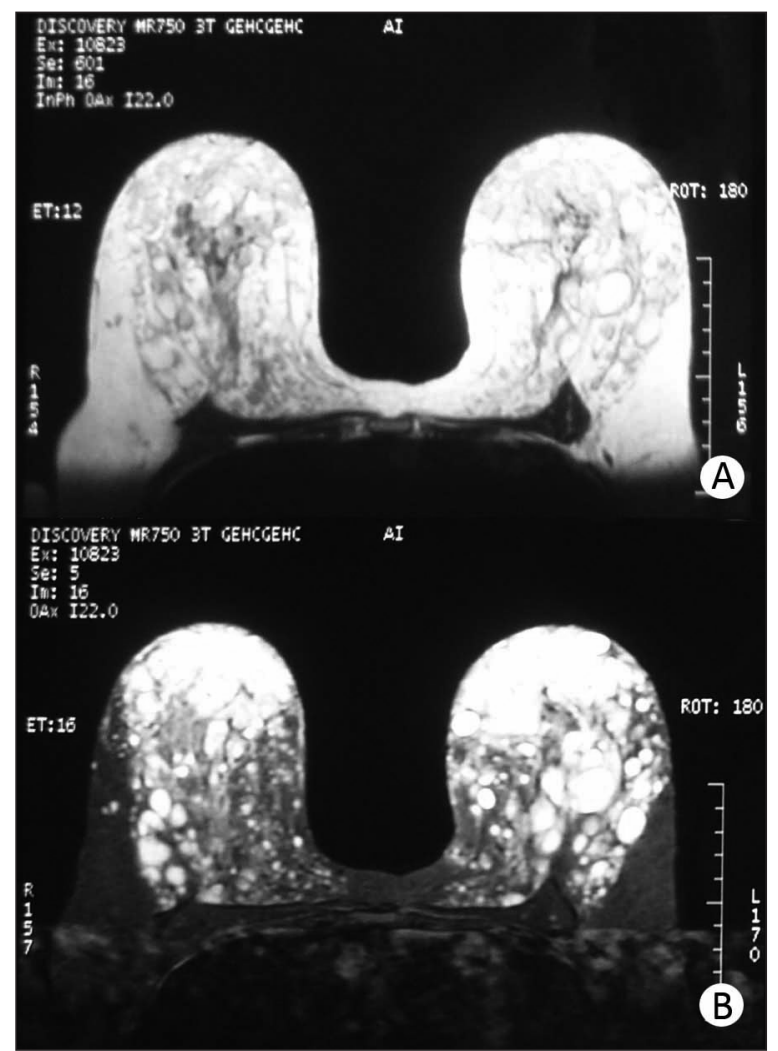

Figure 3: Magnetic resonance imaging image. It showed diffuse multiple nodules in both breasts with intermediate signal intensity on the T1-weighted image (a) and high signal intensity on the T2-weighted image (b). Skin, nipple areola complex and axillary lymph nodes of both breasts were within normal limits

\section{DISCUSSION}

Silicone products were first developed by the Dow Corning Corporation for military purposes. ${ }^{[4]}$ In 1960, the company created medical-grade silicone, which is pure in quality, sterile and of constant viscosity. ${ }^{[4]}$ It was initially used for waterproofing skin, primarily in burn victims. However, this material was misused by certain physicians and by lay clinics as a cosmetic injection material, especially for breast augmentation. ${ }^{[4]}$

Injection of Silicone into the breast tissue for augmentation has been notoriously related to various complications. Most common are the formation of Silicone granuloma and Silicone mastitis. ${ }^{[3,5,6]}$ Nevertheless, the development of symptoms is different for each individual. Some patients may live with injectable Silicone inside their body without any serious symptoms (asymptomatic).

The main concern of surgeons and patients is the possibility of developing cancer in breasts with

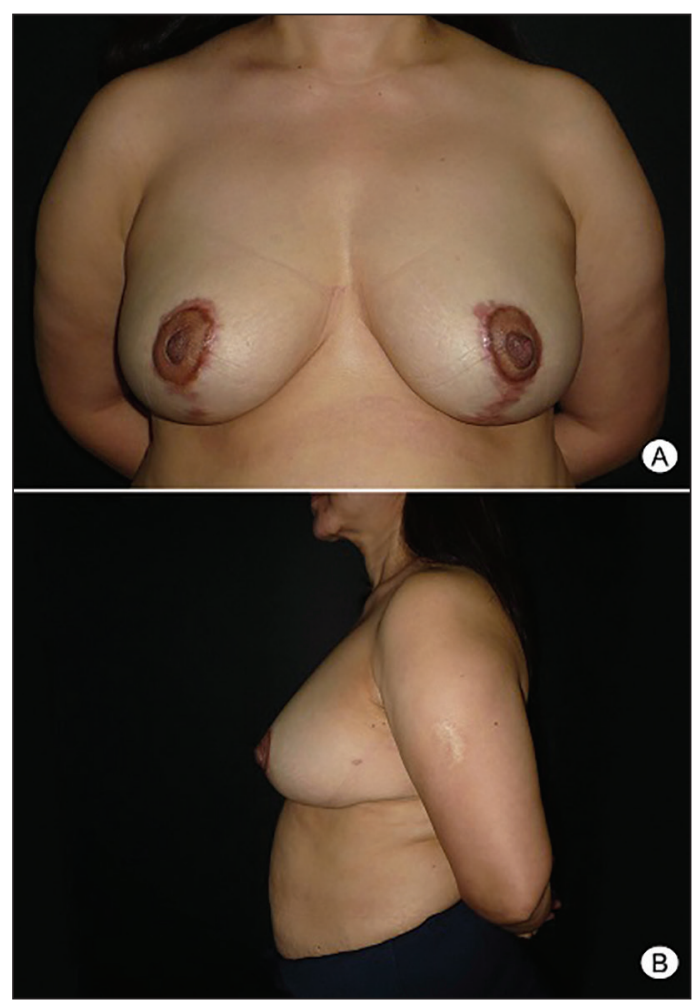

Figure 4: Twenty-two-month postoperative view. One year after surgery, the patient gave birth and gained $10 \mathrm{~kg}$ since the surgery. She was satisfied with the result; hypertrophic scar formation was treated with silicone gel. (a) Anterior view (b) lateral view

Silicone injection. Several studies have tried to relate liquid Silicone injection and the occurrence of malignancy yet their causal relationship has not been proven. ${ }^{[5,6]}$ Risk factors for breast cancer such as age, family history of breast cancer, cancer-predisposing BRCA mutations, nulliparity and the use of hormonal therapy may play a more important role than Silicone injection alone in regards to the incidence of breast cancer.

It is widely accepted that the use of injected materials can obscure early detection of breast cancer by means of clinical breast examination (CBE) and routine breast imaging (mammography and ultrasonography); thus diagnosing breast cancer in Silicone-injected patients may be difficult. ${ }^{[6-8]}$ MRI has been recommended as an additional screening tool because it has the ability to detect the breast lesions and differentiate benign and malignant tumours in the breasts from injectable materials including Silicone..$^{[7,8]}$

A cost-effectiveness analysis study suggested the strategy of alternating between MRI and regular screening (i.e., a combination of mammography and 
CBE) every other year for women at 20-25\% lifetime risk of breast cancer. ${ }^{\left[{ }^{[9}\right.}$ However, due to the differences in study population, this recommendation cannot be adopted directly for women with a history of Silicone injection and further study is needed for this specific population.

To manage asymptomatic Silicone-injected breasts, Chiu et al. ${ }^{[1]}$ recommended follow-up while Chuangsuwanich et al. ${ }^{[10]}$ encouraged prophylactic skin/nipple sparing mastectomy. In our opinion, skin/nipple sparing mastectomy procedure cannot totally remove the injectable materials because they may have infiltrated the skin and NAC. Consequently, the patients still have a chance to develop breast cancer. Moreover, it is difficult to recommend mastectomy in breast-oriented (beauty conscious) patients. It was the patients' decision to choose breast reduction even after they were explained in detail the risks and treatment options. Therefore, we decided to perform breast reduction in our patient after malignancy had been excluded by MRI. Even though it is not commonly implemented in Silicone-injected breasts, it has been performed by Cárdenas-Camarena ${ }^{[2]}$ on his patients who had a history of Silicone injection but did not agree to have a total mastectomy.

In the author's opinion, skin-only mastopexy is not suggested in this case because the breasts will be difficult to elevate and mould due to the presence of granulomata. Therefore, breast reduction is a more suitable option to improve aesthetic appearance.

Obviously, this surgery does not modify the detection of breast cancer or prevent the occurrence of complications in the future because the Silicone materials cannot be completely removed from the breasts. However, this procedure increased our patients' satisfaction with their breast appearance and consequently improved their quality of life (QOL). Their satisfaction overwhelmed the concern to live with the remaining Silicone material. Studies have proven that breast reduction surgery significantly improves both satisfaction with breast appearance and QOL of the patients..$^{[11]}$

\section{CONCLUSION}

Reduction mammoplasty may be the alternative option for women with a history of liquid Silicone injection who have no symptoms but desire to preserve their breasts and improve the aesthetic appearance of the breasts. After the procedure, screening MRI may be performed every 2 years to detect the presence of benign and malignant lesions in the future.

\section{Financial support and sponsorship}

Nil.

\section{Conflicts of interest}

There are no conflicts of interest.

\section{REFERENCES}

1. Chiu WK, Lee TP, Chen SY, Li CC, Wang CH, Chen SG. Bilateral breast reconstruction with a pedicled transverse rectus abdominis myocutaneous flap after subcutaneous mastectomy for symptomatic injected breasts. J Plast Surg Hand Surg 2012;46:242-7.

2. Cárdenas-Camarena $\mathrm{L}$. Managing the mammary gland infiltrated with foreign substances: Different surgical alternatives. Ann Plast Surg 2009;62:621-6.

3. Liu S, Lim AA. Evaluation and treatment of surgical management of silicone mastitis. J Cutan Aesthet Surg 2012;5:193-6.

4. Peters W, Fornasier V. Complications from injectable materials used for breast augmentation. Can J Plast Surg 2009;17:89-96.

5. Echo A, Otake LR, Mehrara BJ, Kraneburg UM, Agrawal N, $\mathrm{Da}$ Lio $\mathrm{AL}$, et al. Surgical management of silicone mastitis: Case series and review of the literature. Aesthetic Plast Surg 2013;37:738-45.

6. Ko C, Ahn CY, Markowitz BL. Injected liquid silicone, chronic mastitis, and undetected breast cancer. Ann Plast Surg 1995;34:176-9.

7. Cheung YC, Chen SC, Lo YF. Enhanced MRI and MRI-guided interventional procedures in women with asymptomatic silicone-injected breasts. ScientificWorldJournal 2012;2012:549801.

8. Leibman AJ, Misra M. Spectrum of imaging findings in the silicone-injected breast. Plast Reconstr Surg 2011;128:28e-9e.

9. Ahern $\mathrm{CH}$, Shih $\mathrm{YC}$, Dong $\mathrm{W}$, Parmigiani G, Shen $\mathrm{Y}$. Cost-effectiveness of alternative strategies for integrating MRI into breast cancer screening for women at high risk. $\mathrm{Br} \mathrm{J}$ Cancer 2014;111:1542-51.

10. Chuangsuwanich $A$, Warnnissorn M, Lohsiriwat V. Siliconoma of the breasts. Gland Surg 2013;2:46-9.

11. Coriddi M, Nadeau M, Taghizadeh M, Taylor A. Analysis of satisfaction and well-being following breast reduction using a validated survey instrument: The BREAST-Q. Plast Reconstr Surg 2013;132:285-90. 